\title{
Erratum to: Whey: Review. Part 1: Classification, Composition, Properties, Derivatives, and Application
}

\author{
I. V. Paladii ${ }^{a}$, E. G. Vrabie ${ }^{a, *}$, K. G. Sprinchan ${ }^{a}$, and M. K. Bologa ${ }^{a}$ \\ ${ }^{a}$ Institute of Applied Physics, Chisinau, MD-2028 Republic of Moldova \\ *e-mail:vrabie657@yahoo.com \\ Submitted November 18, 2021; accepted for publication November 18, 2021
}

DOI: $10.3103 / \mathrm{S} 1068375521060132$

The title of the article should read as follows:

Whey: Review. Part 1: Classification, Composition, Properties, Derivatives, and Application The original article can be found online at https://doi.org/10.3103/S1068375521050112 